\title{
STATISTICAL TABLES FOR THE YEAR I92I
}

From the Ear and Throat Department, Royal Infirmary, Edinburgh; under the charge of A. Logan Turner, M.D., F.R.C.S.E.

By DONALD WATSON, F.R.C.S. Eng.

AFFECTIONS OF THF NOSE (1277).

I. The External Nose and Nasal Vestibule.

Nasal Deformity .

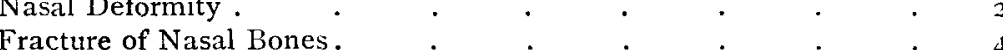

Injury to Nose

Dermatitis of Vestibule . $\quad . \quad$. $\quad . \quad$. $\quad . \quad . \quad 57$

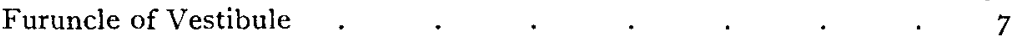

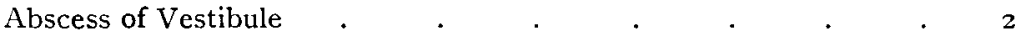

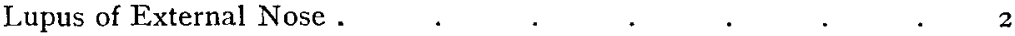

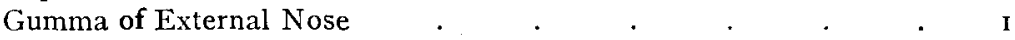

Sebaceous Adenoma $\quad . \quad$. $\quad . \quad$. $\quad . \quad$. $\quad . \quad$ I

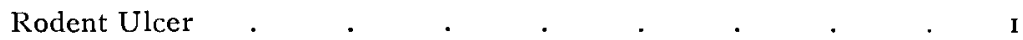

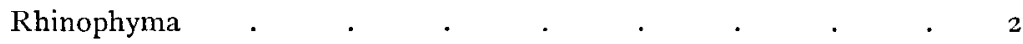

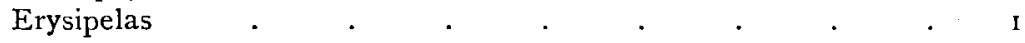

II. The Nasal Cavities.

Foreign Bodies in Nose .

Acute, Subacute, and Chronic Rhinitis. . . . . . II7

Inferior Turbinal Enlargement . . . . . . . . . 280

Synechia between Septum and Turbinal . . . . 2

Nasal Polypi and Polypoid Middle Turbinals . $\quad$. $\quad . \quad$. 94

Atrophic Rhinitis (Non-fœtid) . . . . . . . . 32

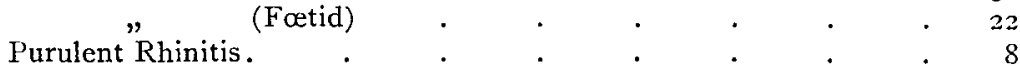

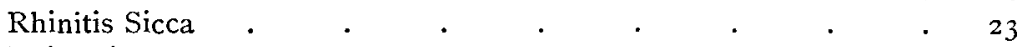

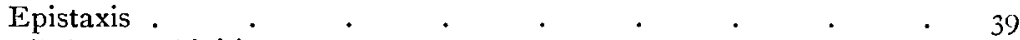

Fibrinous Rhinitis $\quad . \quad$. $\quad . \quad$. $\quad . \quad$. $\quad . \quad$ I

Nasal Diphtheria $\quad . \quad$. $\quad . \quad$. $\quad$. $\quad . \quad$. 1

Deflection of Septum to Right . . . . . . . . $\quad$ I8I

$" \quad, \quad$ Left . . . . . . . . . 184

Perforation of Septum Irregular

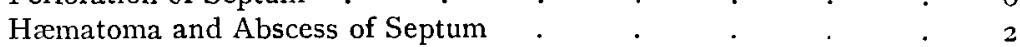

Bleeding Polypus of Septum $\quad$. $\quad$. $\quad$. $\quad$. $\quad$. $\quad$. 2

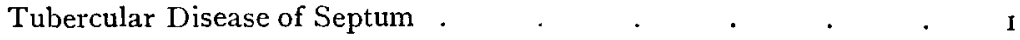

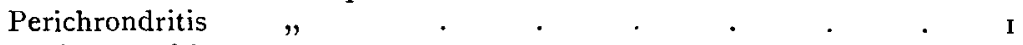

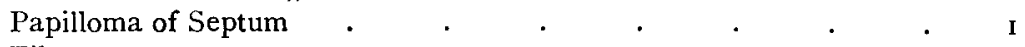

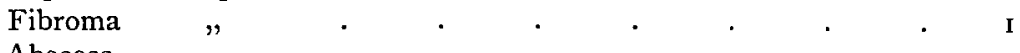

Abscess $"$. 


\section{Statistical Tables for the Year I92 I}

Lupus of Nasal Mucous Membrane . $\quad$. $\quad$. 5

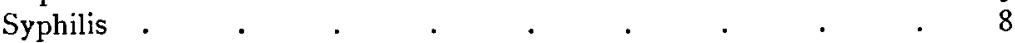

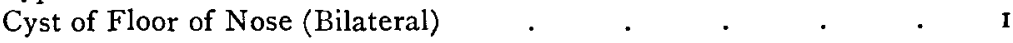

Malignant Tumours :--

Sarcoma (Myeloid) .

Sarcomatous Degeneration of Myxo-fibroma

Nasal Neurosis (including Asthma) . . . . . 8

Anosmia . . . . . . . . . . . . 3

Parosmia . $\quad . \quad$. $\quad . \quad$. $\quad . \quad$. $\quad . \quad$.

Spheno-palatine Ganglion Neurosis . $\quad$. $\quad$. $\quad$. $\quad$ - I

I 190

THE NASAL ACCHSSORY SINUSES (84).

Acute Antral Catarrh

"Suppuration

Chronic Antral Catarrh .

"Suppuration . . . . . . . $\quad .32$

Acute Ethmoidal Suppuration . $\quad$. $\quad$. $\quad$. $\quad$. $\quad$. 4

Chronic

"Antro-Ethmoidal Suppuration .

Acute Frontal Sinus Suppuration

Chronic Frontal and Antral Suppuration

" , Antral, and Ethmoidal Suppuration .

Chronic Sphenoidal Sinus Suppuration .

Pansinusitis

Naso-antral (Choanal) Polypi

Dental Cyst, invading Antrum .

Osteoma of Frontal Sinus (left) .

Mucocele of

Malignant Tumours :-

Squamous Epithelioma of R. Antrum

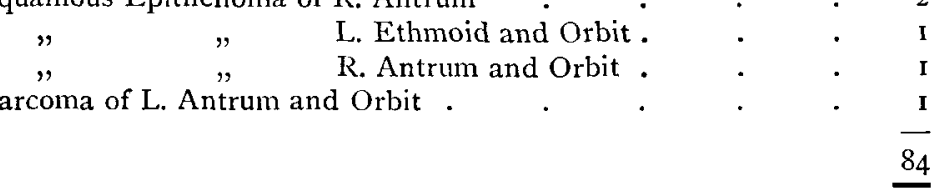

DISEASES OF NASO-PHARYNX, PHARYNX, AND FAUCES (1528).

Congenital Atresia of Choanæ . . . . . . . . I

Adenoids and Enlarged Tonsils. . . . . . . 1350

Acute Tonsillitis . $\quad . \quad$. $\quad . \quad$. $\quad . \quad$. $\quad .25$

Vincent's Angina . $\quad . \quad$. . . . . . . . .

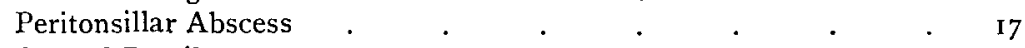

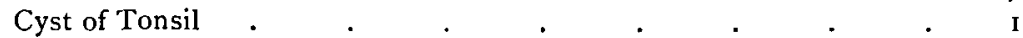

Acute Pharyngitis . . . . . . . . 10

Chronic Catarrhal Pharyngitis (including Granular) . . . 45

Pharyngitis Sicca $\quad . \quad$. $\quad . \quad$. $\quad . \quad$. $\quad . \quad 15$

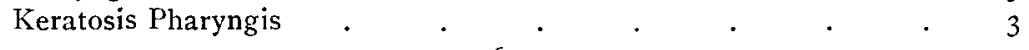




\section{Donald Watson}

Hypertrophy of Lingual Tonsil .

Nasopharyngeal Catarrh

Tubercular Disease of Pharynx .

Secondary Syphilis of Fauces and Pharynx

Tertiary

Malignant Tumours of Fauces and Pharynx

Foreign Bodies in Fauces and Pharynx

Fibroma of Nasopharynx

Sensory Neurosis .

DISEASES OF THE MOUTH (21).

Cleft Palate

Simple Ulcer of Tongue .

Acute Glossitis

Tertiary Syphilis of Mouth, Tongue, and Palat

Malignant Disease of Tongue and Palate

Injury to Mouth and Palate

Salivary Calculus .

Periodontal Abscess

Neurosis of Mouth and Tongue.$$
8
$$

$$
4
$$




\section{Statistical Tables for the Year 192I}

IV. Affections of Laryngeal Nerves.

Functional Aphonia

Abductor Paralysis of L.V.C.

,,$\quad$ R.V.C.

Recurrent Paralysis of L.V.C.

"

R.V.C.

Bilateral Abductor Paralysis

Sensory Laryngeal Neurosis

I I

I

2

6

I

2

V. Miscellaneous.

Congenital Laryngeal Stridor

Stenosis of Larynx

Subglottic Hypertrophy .

Subglottic CEdema of Larynx (unknown cause)

Injury to Larynx (cut-throat)

Inspiratory Spasm following Diphtheria

Simple and Exophthalmic Goitre

Purulent Tracheitis

AFFECTIONS OF LARYNGHAL-PHARYNX AND CFSOPHAGUS (37).

Malignant Stricture of Laryngeal-pharynx (Squamous Epithelioma) . 3

Cardiospasm

Functional Dysphagia (shell shock)

Spasmodic Stricture (upper end)

Traumatic

Malignant Stricture of Esophagus :-

Cervical

Intra-thoracic

Foreign Bodies .

Hæmorrhage from Esophagus .

AFFECTIONS OF THE TAR (1803).

I. The External Ear.

Injuries to External Ear .

Cerumen .

Furunculosis

Otitis Externa

Hyperostosis

Fibro-cutaneous Stenosis of Auditory Meatus .

Erysipelas of External Ear

Foreign Bodies 


\section{Donald Watson}

Sebaceous Cyst of Auricle

Perichondritis

Herpes

Aural Neurosis

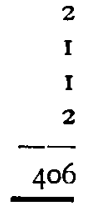

II. The Middle Ear Cleft.

Traumatic Rupture of Tympanic Membrane . $\quad$. $\quad$. $\quad$. 4

Eustachian Obstruction . . . . . . . . . $\quad$ I85

Acute Non-suppurative Otitis Media . $\quad . \quad$. $\quad . \quad$. 2 I

Chronic

Acute Suppurative Otitis Media :-

Right.

Left .

Bilateral

Chronic Suppurative Otitis Media :--

Right.

Left

Bilateral

Sequelæ of Chronic Suppurative Otitis Media :-

Right.

Left .

Bilateral

Acute Middle Ear Suppuration with Mastoid Complication :-

Right.

Left .

Bilateral

Chronic Middle Ear Suppuration with Mastoid Complication :--

Right.

Left .

Bilateral

Tubercular Middle Ear Suppuration :-

Right.

Left

III.

Otosclerosis

Mixed Middle and Inner Ear Deafness.

IV. Internal Ear Affections:

Congenital (including deaf-mutism)

Traumatic (following shell explosion)

Occupational

(following other injuries)

Functional 


\section{Statistical Tables for the Year $\mathbf{1 9 2} \mathbf{I}$}

Senile Changes .

Chronic Latent " " . . . . . 3

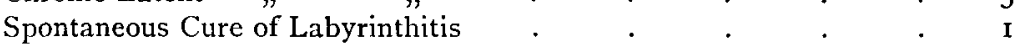

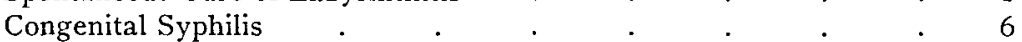

Acquired Syphilis $\quad . \quad$. $\quad$. $\quad$. $\quad . \quad$. $\quad .7$

Nerve Deafness due to Toxæmia (including specific fevers) . . 6

Cerebello Pontine Tumour and Tumour of Eighth Nerve . . 2

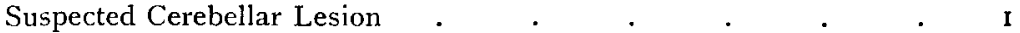

Unknown Causes of Nerve Deafness ' . $\quad . \quad$. $\quad . \quad$. $\quad .56$

INTRACRANIAL COMPLICATIONS OF SUPPURATIVE OTITIS MEDIA.

Three cases complicating Acute Suppurative Otitis Media :--

Extra-dural Abscess in Middle and Posterior Fossæe (Right ear).

Extra-dural Abscess and Cerebellar Abscess (Left ear) .

Jugular Bulb Thrombosis, Lepto-meningitis, and Acute Septicæmia (Left ear)

Recoveries: 1.-Extra-dural Abscess in Middle and Posterior Fossæ.

Deaths : 2.-The Cerebellar Abscess and Jugular Bulb Thrombosis Cases.

Three cases complicating Chronic Suppurative Otitis Media :-

Peri-sinus Abscess and Cerebellar Abscess (Right and Left ears)

Temporo-sphenoidal Abscess and Lepto-meningitis (Right ear).

Recoveries: I.--Peri-sinus and Cerebellar Abscess.

Deaths: 2.-Cerebellar and Temporo-sphenoidal Abscess Cases.

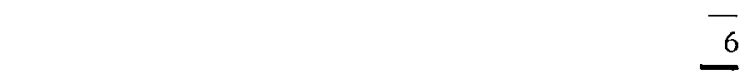

MISCFLLANFOUS CASES (183).

These include cases sent from other wards in the hospital with negative findings, enlarged cervical glands, skin diseases, headaches of unknown origin, eye cases, etc. ..$\quad \cdot \quad \frac{1}{83}$

\section{TABLE OF OPFRATIONS}

The Nose.

Fracture of Nasal Bones (rectified)

Wart removed

Cyst of Floor of Nose removed .

Abscess and Hæmatoma of Septum 


\section{Donald Watson}

Submucous Resection of Septum $\quad$. $\quad$. $\quad$. $\quad$. 199

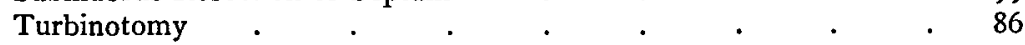

Nasal Polypi (including return cases) . $\quad . \quad$. $\quad . \quad$ I 32

Curetting for Lupus $\quad$. $\quad$. $\quad$. $\quad$. $\quad$. $\quad$. $\quad$. 4

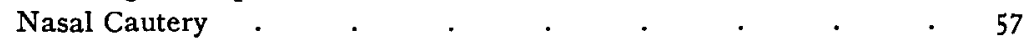

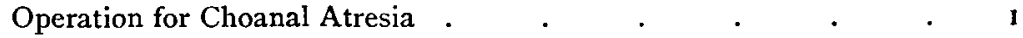

Foreign Bodies removed from Nose $\quad$. $\quad$. $\quad$. $\quad$. $\quad$. 5

Intra-nasal Dacryocystitis (West's Operation) . . . . . 6

Injection of Spheno-palatine Ganglion (Sluder) $\quad . \quad$. $\quad$ I

498

Operations on Nasal Accessory Sinuses.

Proof Puncture of Antrum . . . . . . . . I2I

Intra-nasal Operation on Antrum $\quad . \quad$. $\quad . \quad . \quad . \quad$ I

Radical Operation on Antrum (including naso-antral Polypi). $\quad 4_{4}$

Intra-nasal Operation on Frontal Sinus . . . . . 2

Radical " " $"$. . . . . . . 1

Intra-nasal Operation on Ethmoid Cells $\quad . \quad+\quad . \quad . \quad . \quad 16$

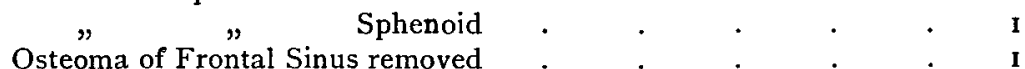

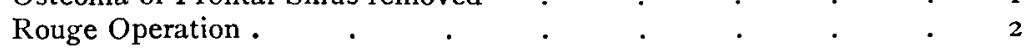

Operations on Mouth and Pharynx.

Tonsils and Adenoids removed (Guillotine and Curette) . . I200

Tonsils dissected out (Scissors and Snare) . . . . . 6I

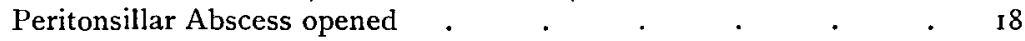

Retropharyngeal Abscess opened $\quad . \quad$. $\quad . \quad$. $\quad . \quad$. I

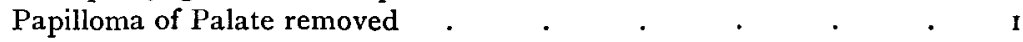

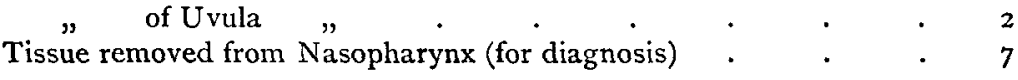

1290

Operations on Larynx, Trachea, and Gsophagus.

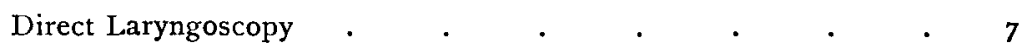

Suspension Laryngoscopy :-

Examination .

Simple Tumour of Vocal Cords

Foreign Body removed

Dilatation of Stenosis

Esophagoscopy :-

Examination .

Removal of Foreign Bodies . $\cdot 46$

Bronchoscopy

Tracheotomy 


\section{Statistical Tables for the Year 192 I}

Operations on the Far.

Furunculosis opened

Paracentesis

Sebaceous Cyst of Auricle

Aural Polypi curetted

Glandular Abscess over Mastoid

Foreign Bodies removed.

Plastic Operations

Schwartze Operation on Mastoid

Modified Radical Operation on Mastoid

Radical Operation on Mastoid .

Labyrinthotomy .

Translabyrinthine Drainage

Extra-dural Peri-sinus Abscess .

Extra-dural Abscess in Middle and Posterior Fossæ

Cerebellar Abscess opened

Temporo-sphenoidal Abscess opened

Internal Jugular Vein ligatured.

Jugular Bulb Operation.

\section{Anæesthetics Administered.}

Ethyl Chloride

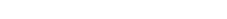

Chloroform followed by Ether

Local Anæsthesia

Number of new patients attending the Department 